\title{
Introduction: Menstruation as Fundamental
}

\author{
Inga T. Winkler
}

Most articles on menstruation start by pointing out that menstruation is a normal biological process. This, of course, is true. But at the same time, menstruation is so much more for many people; in fact, it is fundamental. Menstruation unites the personal and the political, the intimate and the public, and the physiological and the socio-cultural.

Menstruation is fundamental because it either facilitates or impedes the realization of a whole range of human rights. In 2019, a group of United Nations human rights experts acknowledged that

The stigma and shame generated by stereotypes around menstruation have severe impacts on all aspects of women's and girls' human rights, including their human rights to equality, health, housing, water, sanitation, education, freedom of religion or belief, safe and healthy working conditions, and to take part in cultural life and public life without discrimination. (United Nations 2019)

Because these dimensions of menstruation in different spheres of life shape lived experiences, we begin this Handbook with a series of chapters that focus on the voices and lived experiences of menstruators in different contexts. They all menstruate, but their unique socio-cultural, religious, and political contexts differentially shape and provide meaning to their experiences.

The coherence of this set of chapters lies in its deliberate diversity-in content, experiences, formats, and authors. Regarding the latter, while I aimed to include an even more diverse representation, I am keen to acknowledge the range of backgrounds of those who wrote for this section across geography, culture, religion, race, ethnicity, caste, age, sexual orientation, and gender identity. Sometimes more explicitly, sometimes more implicitly, they all bring their own lived experiences into their research and writing. 
Not only do the chapters highlight the uniqueness of different experiences, but they also present them in diverse ways. Some chapters are traditional research chapters, others are personal narratives, and yet another takes the form of a conversation between different contributors, which we call "Transnational Engagements" that punctuate each section. As editor, I value these different forms of knowledge and how they contribute to a better understanding of menstruation. I consider this all the more important in such a rapidly emerging field as Critical Menstruation Studies, in which many questions are still underexplored.

To begin to address these questions, contributors in this section address menstruation in different conditions, including informal settlements, homelessness, detention, disability, child marriage, and migration. The latter chapters in this section complement these perspectives by adding the layers of religion, culture, and caste. Annie McCarthy and Kuntala Lahiri-Dutt focus on the experiences of women in Delhi's informal settlements to describe the ways women manage the structural deficits they face, reconfigure notions of privacy, and navigate changing gender relations. The theme of navigating the need for privacy in public space is also central to Shailini Vora's exploration of homelessness for women in Bristol, UK who are conscious of their doubly stigmatized status as 'homeless' menstruators-a precarious reality that forces strategic management and concealment of their menstrual status.

The unwanted publicness of menstrual experiences is further put into stark relief by Chandra Bozelko speaking about her experience living in detention, most poignantly, the shame and humiliation of staining her clothes and having to ask male guards for tampons and pads. Tomi-Ann Roberts complements this perspective by detailing the experiences of women deprived of liberty who undergo a degrading strip search en masse. She argues that this is a uniquely misogynist form of punishment which women experience against the background of the objectification and self-objectification of their bodies. Trans and genderqueer menstruators also deal with unwanted publicness as well as social expectations, standards of femininity, and a range of constraints in social and physical spheres. S. E. Frank and Jac Dellaria present these in a visual narrative that focuses on everyday experiences.

The power over women's bodies is a central theme in Linda Steele's and Beth Goldblatt's chapter. The authors powerfully demonstrate that women and girls with disabilities are perceived as mentally and physically incapable of meeting gendered norms of menstrual concealment which leads to coercive interventions by parents, carers, medical professionals, and judges, particularly through sterilization. In a different context, Musu Bakoto Sawo presents a narrative of coercion and her journey into forced womanhood. Her story powerfully describes how she turned from a survivor of child marriage into a children's and women's rights activist.

All these chapters show how experiences of menstruation are shaped by gendered expectations about women's bodies in social context. Alex Hawkey's, Jane Ussher's, and Janette Perz's contribution is a potent demonstration 
of these forces as it emphasizes the shifting constructions and experiences of menarche and menstruation from the perspective of migrant and refugee women resettled in Australia and Canada.

As the section proceeds, the frame broadens to offer religious and cultural perspectives on menstruation. Most often, when discussing religion and menstruation, the language is one of restriction and oppression. Ilana Cohen's exploration of the menstrual traditions in both Judaism and Hinduism succeeds in adding complexity to that frame. She examines how menstrual practices contribute to a better understanding of the ways a religious community defines and (re)produces itself. This overview is complemented by two personal narratives that provide additional perspectives on menstruation and religion. Tova Mirvis offers a personal reflection on the Jewish practice of mikvah, or ritual bath after the completion of her menstrual period. She shares her growing doubts about her religious beliefs and laws which required the mikvah, eventually leading her to leave the religious world of which she was a part. Deepthi Sukumar's narrative addresses the intersection of Hinduism, menstruation, and caste. She compellingly details that menstrual restrictions often associated with Hinduism have never affected her, a Dalit. She argues that "caste is her period:" whether menstruating or not, Dalit women are considered 'impure' and 'polluting.'

Alma Gottlieb contributes a chapter that reflects on menstrual taboos. We often hear that menstruation is shrouded in taboos, myths, and silence. But what do we really mean by this claim? In response, Gottlieb disentangles the idea of taboos, taking the reader to the origin of the Polynesian word tapu, which is neither negative nor positive but invokes the notion of a state of being that is too powerful to act on. From there, she discusses a diverse range of encounters with menstruation in various cultures and inserts greater nuance into the discussion on taboos. To conclude, the individuals participating in this section's "Transnational Engagements" on cultural and religious menstrual practices edited by Trisha Maharaj and Inga T. Winkler further the diversity of perspectives. The contributors demonstrate varying perceptions of menstrual practices including how they exercise their agency when deciding if or how to engage in these practices and/or their transformation. This conversation thus productively complicates the too-common depiction of all menstrual practices as restrictions necessarily forced upon women.

The chapters in this section demonstrate the importance-and indeed urgency - of considering the lived experiences of all menstruators. These vary widely and are shaped by a range of different factors including religion, culture, political systems, socialization, caste, disability, place of residence, among many others. In many cases, an intersection of factors such as gender and disability; or gender, religion, and caste determine menstrual experiences. This material offers insights into some individuals' menstrual experiences many of whom are marginalized on different grounds. The chapters in this section are complemented by additional perspectives in other sections of the Handbook, such as the experiences of women and girls in refugee camps described by Siri Tellier 
et al., autistic experiences of menstruation described by Robyn Steward et al., and trans menstruation addressed by Klara Rydström.

What stands out throughout the section are the tensions between 'the public' and 'the private.' Many individuals shared feelings of embarrassment when publicly disclosing their menstrual status or shame when having to request menstrual products. To avoid such discomfort, individuals often seek out privacy when menstruating. This forces us to ask: Why do we think that menstruation should be kept invisible and private? Why is this natural biological process considered embarrassing? And how do gendered social norms and perceptions of modesty inform our understanding of what menstruation 'should be?' In answering these questions, we must be very careful not to impose the burden of transforming societal norms on individuals alone who are often in the most marginalized or vulnerable situations. Such transformation requires us all to contribute to broader societal change.

Menstruation is fundamental because it is ultimately about power relations - the power of the guard in the prison or staff in a homeless shelter to dispense or withhold menstrual products, the power of judges to authorize sterilizations, the power of parents and relatives to force young girls to marry, and the power of religious authorities to expect unflinching conformity with religious norms. Adopting a human rights perspective to addressing menstruation forces us to rethink and shift these power relations. At the core of human rights is the dignity and agency of every individual, and the voices included in this section powerfully demonstrate that such agency can take many different forms: turning from a survivor of child marriage or someone formerly living in detention into advocates whose voices are heard widely; transforming socio-cultural norms; and finding meaning in religious menstrual norms. Considering menstruation as fundamental means to enable women and girls and anyone who menstruates to exercise their agency.

\section{REFERENCE}

United Nations. 2019. “International Women's Day-8 March 2019 Women's Menstrual Health Should No Longer Be a Taboo.” Accessed July 26, 2019. https://www.ohchr.org/EN/NewsEvents/Pages/DisplayNews.aspx?NewsID= 24258\&LangID $=$ E. 
Open Access This chapter is licensed under the terms of the Creative Commons Attribution 4.0 International License (http://creativecommons.org/licenses/ by $/ 4.0 /)$, which permits use, sharing, adaptation, distribution and reproduction in any medium or format, as long as you give appropriate credit to the original author(s) and the source, provide a link to the Creative Commons license and indicate if changes were made.

The images or other third party material in this chapter are included in the chapter's Creative Commons license, unless indicated otherwise in a credit line to the material. If material is not included in the chapter's Creative Commons license and your intended use is not permitted by statutory regulation or exceeds the permitted use, you will need to obtain permission directly from the copyright holder. 